\title{
Humidity adsorption kinetics of calix[4]arene derivatives measured using QCM technique
}

\author{
Salih Okur ${ }^{\mathrm{a}, *}$, Mahmut Kuş $^{\mathrm{b}, * *}$, Faruk Özel $^{\mathrm{b}}$, Vildan Aybek $^{\mathrm{b}}$, Mustafa Yılmaz $^{\mathrm{c}}$ \\ a Izmir Institute of Technology, Department of Physics, Urla, Izmir, Turkey \\ b Selçuk University, Department of Chemical Engineering, Selçuklu, Konya, Turkey \\ ' Selçuk University, Department of Chemistry, Selçuklu, Konya, Turkey
}

\section{A R T I C L E I N F O}

\section{Article history:}

Received 29 May 2009

Received in revised form

22 November 2009

Accepted 29 November 2009

Available online 5 December 2009

\section{Keywords:}

Calix[4]arene

Humidity sensor

Quartz crystal microbalance

\begin{abstract}
A B S T R A C T
This study focuses on the characterization of sulphonated calix[4]arene derivative films coated on a quartz substrate with a thickness of $40 \mathrm{~nm}$ by spin coating method for humidity detection. The humidity adsorption kinetics of the sulphonated calix[4]arene films was investigated by quartz crystal microbalance (QCM) technique. The Langmuir model was used to determine the adsorption rates and Gibbs free energy for various relative humidities between $11 \%$ and $97 \%$. Our reproducible experimental results show that suphonated calix[4]arene films have a great potential for humidity sensing applications at room temperature operations.
\end{abstract}

@ 2009 Elsevier B.V. All rights reserved.

\section{Introduction}

Calixarenes are macrocyclic molecules consisting of several phenol units connected via methylene bridges and they can be easily functionalized. Many studies with these molecules show that the cylindrical-shaped calixarenes of varying cavity sizes can form a variety of host-guest types of inclusion complexes similar to cyclodextrins. However, $\pi-\pi$ interaction is observed in calixarenes due to the benzene groups [1]. Water-soluble calixarenes have been also synthesized and reported by many authors in the literature. Shinkai et al. synthesized water-soluble calixarenes carrying sulfonate groups in 1984 [2].

Thin films of calixarene derivatives have been widely used as chemical sensors, due to their zeolite-like capacity and selectivity. Calixarenes became promising materials for sensor applications due to functional groups at the upper and lower rims, that determine the selectivity in host-guest interactions and physical properties [3-4]. They have been also used as gas or organic solvent vapour sensors [5-7].

Quartz crystal microbalance (QCM) [8-10] and ion-sensitive field-effect transistors (ISFETs) [11] technique have been reported as sensor applications. QCM have been widely employed for the

\footnotetext{
* Corresponding author. Tel.: +90 2327507706.

** Corresponding author. Tel.: +90 3322232131.

E-mail addresses: salihokur@iyte.edu.tr(S. Okur),mahmut_kus@yahoo.com (M. Kuş).
}

determination of metals deposited onto the crystal and investigations of the kinetics of adsorption of adsorbate molecules. QCM technique is a powerful technique for determining the sensing properties of materials before a sensor device design during development stages. Although it is known that some of calixarene derivatives adsorb water molecules [12], we have not reached any report on humidity sensing properties, adsorption kinetics of calixarene based on QCM techniques. In this work, we have used QCM technique to investigate sensing properties of calix[4]arene films with carboxylic and sulphonic acid groups which are sensitive to water molecules.

QCM is based on frequency shift of coated quartz crystal with sensing element due to adsorption of humidity atoms on the surface of the sensing material [13]. The mass change $(\Delta m)$ on surface of the quartz crystal is calculated by using Sauerbrey equation [13] from the frequency change $(\Delta f)$

$$
\Delta m=-\frac{A \sqrt{\mu \rho}}{2 f_{0}^{2}} \times \Delta f=-C \times \Delta f
$$

where $f_{0}$ is the resonant frequency of the fundamental mode of the QCM crystal, $A$ is the area of the gold disk coated onto the crystal, $\rho$ is the density of the crystal, and $\mu$ is the shear modulus of quartz. Hence the frequency shift is directly proportional to the adsorbed mass on the calix[4]arene modified gold QCM electrodes.

Calix[4]arene films were prepared on gold coated QCM electrodes using spin coating method at $2000 \mathrm{rpm}$. The change of resonance frequency of QCM was monitored with increasing relative humidity (RH) up to $97 \%$. The adsorption kinetic parameters 


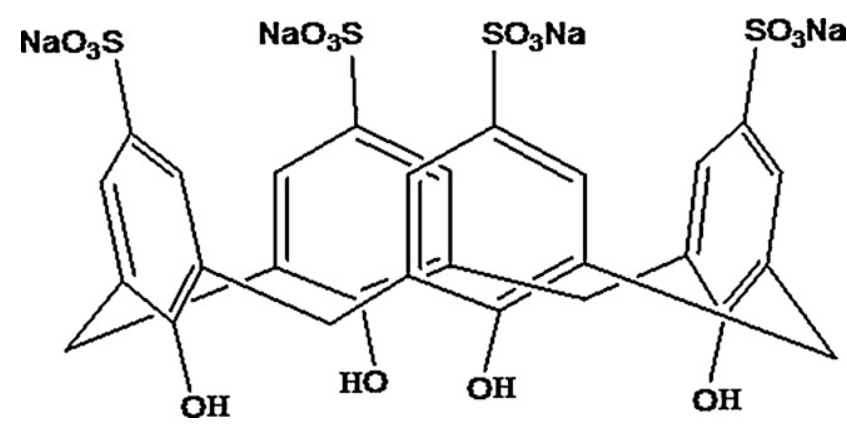

Fig. 1. Chemical structure of sulphonated calix[4]arene.

determined by using Langmuir model show that the calix[4]arene films have strong affinity to water vapor molecules between $22 \%$ and $94 \%$ relative humidity.

\section{Experimental}

\subsection{Synthesis and film preparation of sulphonated calix[4]arene}

Suphonated calix[4]arene was synthesized according to previously published procedure [2-12,14]. Molecular structure of calix[4] arene derivative is given in Fig. $1.1 \mathrm{mg} / \mathrm{ml}$ calix[4] arene was dissolved in de-ionized water. $5 \mu$ l of solution was spin-coated on to quartz crystal with $2000 \mathrm{rpm}$. After drying at room conditions, it was kept in dessicator at room temperature for $3 \mathrm{~h}$. Then it is used for measurements. The thickness of films were measured with a Dektak profilometer from Veeco and found to be $40 \mathrm{~nm}$.

\subsection{Humidity measurement technique:}

A time-resolved electrochemical quartz crystal microbalance (EQCM) with the model of CHI400A Series from $\mathrm{CH}$ Instruments (Austin, USA) has been used to measure the change in the resonance frequency of quartz crystals between gold electrodes via both serial and USB interface connected to a computer. The QCM works with oscillation frequencies between $7.995 \mathrm{MHz}$ and $7.950 \mathrm{MHz}$. The density $(\rho)$ of the crystal is $2.684 \mathrm{~g} / \mathrm{cm}^{3}$, and the shear modulus $(\mu)$ of quartz is $2.947 \times 10^{11} \mathrm{~g} / \mathrm{cm} \mathrm{s}^{2}$. Around oscillation frequency of $7.995 \mathrm{MHz}$, a net change of $1 \mathrm{~Hz}$ corresponds to $1.34 \mathrm{ng}$ of materials adsorbed or desorbed onto the crystal surface of an area of $0.196 \mathrm{~cm}^{2}$.

Gold coated quartz crystal electrodes were placed into ethanol and ultrasonically cleaned, then rinsed by de-ionized water. After
Table 1

The calculated vapor molar concentration $C$ using ideal gas equation $(P V=n R T)$ at the corresponding partial pressure for the relative humidity measured at the equilibrium point.

\begin{tabular}{lll}
\hline Saturated solutions & Relative humidity (\%) & Concentration $(\mathrm{M})$ \\
\hline $\mathrm{LiCl}$ & 11 & $1.06 \mathrm{E}-04$ \\
$\mathrm{KAc}$ & 22 & $2.11 \mathrm{E}-04$ \\
$\mathrm{~K}_{2} \mathrm{O}_{3}$ & 43 & $4.13 \mathrm{E}-04$ \\
$\mathrm{Mg}\left(\mathrm{NO}_{3}\right)_{2}$ & 55 & $5.28 \mathrm{E}-04$ \\
$\mathrm{NaCl}$ & 75 & $7.20 \mathrm{E}-04$ \\
$\mathrm{KCl}$ & 84 & $8.06 \mathrm{E}-04$ \\
$\mathrm{KNO}_{3}$ & 94 & $8.37 \mathrm{E}-04$ \\
$\mathrm{~K}_{2} \mathrm{SO}_{4}$ & 97 & $9.31 \mathrm{E}-04$ \\
\hline
\end{tabular}

dried with argon gas, quartz crystal was placed into the Teflon housing and the reference frequency was recorded.

A closed box partly filled with saturated salt solutions generates relative humidity in the free room above the salt with good accuracy. The value of the relative humidity depends on the type of salt used as given in Table 1 [15]. Fig. 2 shows the experimental setup to measure the adsorption kinetics of calix[4]arene films above saturated $\mathrm{LiCl}(11 \% \mathrm{RH})$ and $\mathrm{K}_{2} \mathrm{SO}_{4}(97 \% \mathrm{RH})$ aquatic solution level inside a half-filled closed container using hybrid system of QCM electrodes and a commercial humidity sensor. Both signals coming from QCM and RH sensor were simultaneously measured during the adsorption process. Both the relative humidity and temperature were also recorded during measurements to maintain the temperature. For this purpose, a EI-1050 selectable digital relative humidity and temperature probe with a response time of $4 \mathrm{~s}$ and a resolution of $0.03 \%$ RH was used with a USB controlled LabJack U12 ADC system combined with a single chip sensor module (SHT11) manufactured by Sensirion (Staefa, Switzerland).

\section{Results and discussion}

Fig. 3(a) and (b) shows the frequency response of calix[4]arene film covered QCM during adsorption process at fixed point relative humidity conditions between $11 \%$ and $97 \%$ RH. In Fig. 3(a) QCM frequency shifts after adsorption and desorption cycles between $11 \% \mathrm{RH}$ and various $\mathrm{RH}$ values up to $97 \%$ recovers back to the initial value. In Fig. 3(b) the relative humidity is increased and decreased step by step between $11 \%$ and $97 \%$ RH for an equal time intervals to see if there is any residual adsorbed mass left on the calix[4]arene film. Both measurements show no hysteresis after the moist adsorption and desorption process. The adsorption and desorption data taken from Fig. 3(a) and (b) show an exponential dependence on relative humidity RH as shown in Fig. 3(c).

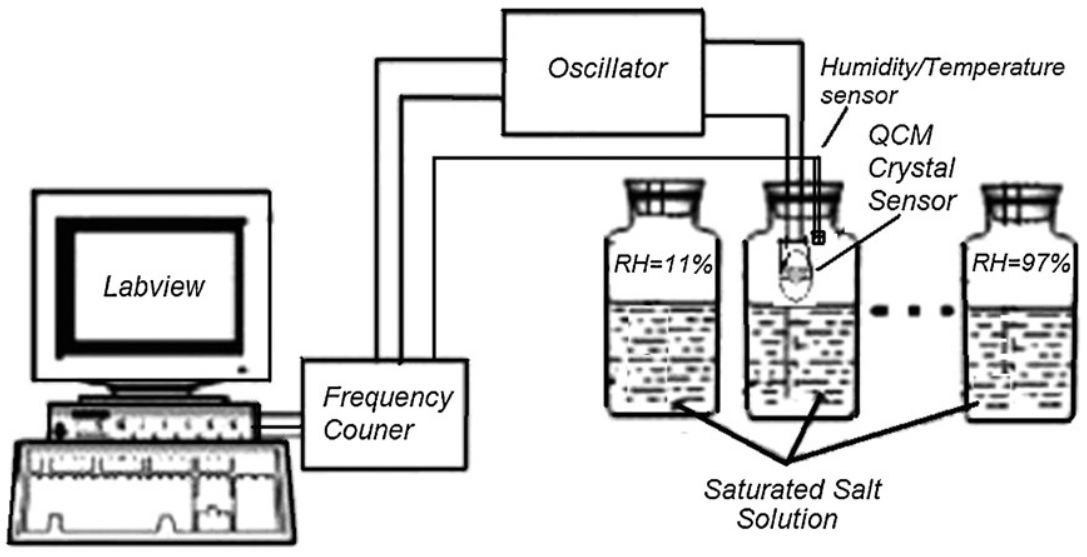

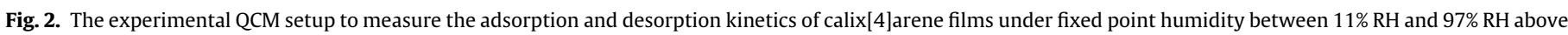
a saturated salt solution inside a closed container. 

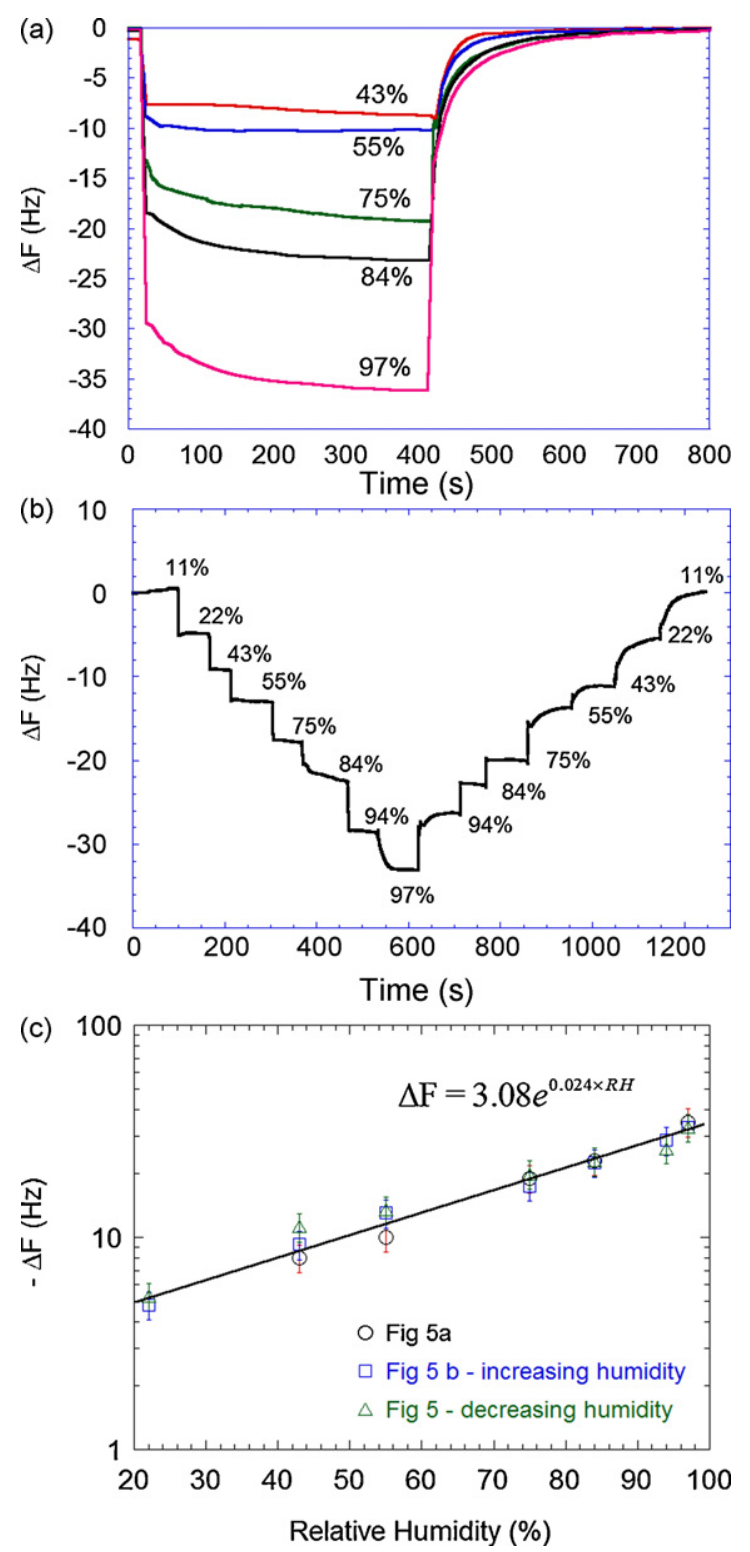

Fig. 3. QCM frequency shifts for adsorption and desorption cycles between $11 \% \mathrm{RH}$ and various RH values (a), QCM frequency shifts $(\mathrm{Hz})$ as a function of time (s) for different increasing and decreasing relative humidity values between $11 \%$ and $97 \%$ $\mathrm{RH}$. The adsorption and desorption data taken from Fig. 3(a) and (b) show a linear dependence on relative humidity when the frequency shifts are taken as logarithmic (c). The magnitude of the error bars is chosen as $15 \%$.

Langmuir adsorption isotherm model is frequently used to describe adsorption kinetics of gas molecules onto organic or inorganic films [16-19]. According to this model, the rate of surface reaction for forming a monolayer on the surface is given by,

$\frac{d \theta}{d t}=k_{\mathrm{a}}(1-\theta) C-k_{\mathrm{d}} \theta$

where $\theta$ is a unitless quantity, which express the fraction of surface coverage, $C$ is the gas concentration in the air, $k_{\mathrm{a}}$ and $k_{\mathrm{d}}$ are the rate constants for the adsorption and desorption processes, respectively. Integration of Eq. (2) leads to:

$\theta(t)=K^{\prime}\left(1-e^{-k_{\mathrm{obs}} t}\right)$ where $K^{\prime}$ is the association constant and $k_{\text {obs }}$ is the inverse of the relation time defined as following;

$K^{\prime}=\frac{C}{C+\left(k_{\mathrm{d}} / k_{\mathrm{a}}\right)} \quad$ and $\quad k_{\mathrm{obs}}=k_{\mathrm{a}} C+k_{\mathrm{d}}$

In this study, QCM has been used to measure the fractional coverage $\theta$ as a function of time during the adsorption of water vapor molecules by calix[4]arene film, while the increase in the frequency shift reflects the molecular mass uptake or loss. Hence the difference between the oscillation frequency shift $(\Delta f)$ of coated and uncoated QCM is directly proportional to the adsorbed mass of moisture molecules. The relationship between the surface adsorption kinetics and frequency shift $(\Delta f)$ of QCM can be expressed as following;

$\frac{d \Delta f}{d t}=\left(\Delta f_{\max }-\Delta f\right) k_{\mathrm{a}} C-k_{\mathrm{a}} \Delta f$

where $\Delta f$ and $\Delta f_{\max }$ are the QCM resonance frequency shifts, $k_{\mathrm{a}}$ and $k_{\mathrm{d}}$ are the adsorption and desorption rate constants, $C$ is the concentration of water molecules in air, $t$ is the time. The standard steam tables were used to determine the partial pressure of water vapor at related temperature [20]. A very convenient method to calibrate humidity sensors is the use of saturated salt solutions. At any temperature, the concentration of a saturated solution is fixed and does not have to be determined. By providing excess solute, the solution will remain saturated even in the presence of modest moisture sources and sinks. When the solute is a solid in the pure phase, it is easy to determine that there is saturation. The saturated salt solution, made up as a slushy mixture with distilled water and chemically pure salt, is enclosed in a sealed metal or a glass chamber [15]. Temperature was kept constant during measurements around $22^{\circ} \mathrm{C}$. The vapor molar concentration $C$ was calculated from the ideal gas equation $(P V=n R T)$ at the corresponding partial pressure for the relative humidity measured at the equilibrium point as shown in Table 1.

The time variation of the change in the frequency due to adsorption can be obtained as following,

$\Delta f(t)=\Delta f_{\max } K^{\prime}\left(1-e^{-k_{\mathrm{obs}} t}\right)$

In the QCM technique, the frequency shift is proportional with the change in the absorbed mass by the film on the QCM electrodes. The time dependent frequency shift can be fitted by Langmuir isotherm adsorption. From the curve fit, association constant $\left(K^{\prime}\right)$ of the water vapour molecules is found as 20.5 , and $k_{\mathrm{obs}}=0.051 \mathrm{~s}^{-1}$.

Using Sauerbrey relation given in Eq. (1), $(\Delta m=$ $-(1.34 \mathrm{ng} / \mathrm{Hz}) \Delta f)$, the time dependent variation of mass of the adsorbed water vapour molecules on the calix[4]arene film surface $\Delta m_{t}$ can be defined as following:

$$
\begin{aligned}
& \Delta m_{t}=\Delta m_{\infty}\left(1-e^{-t / \tau}\right) \\
& \tau^{-1}=k_{\mathrm{a}}\left[\text { water vapour molecules] }+k_{\mathrm{d}}\right.
\end{aligned}
$$

$\Delta m_{\infty}$ is the maximum adsorbed amount of the humidity molecules on the surface at $t \rightarrow \infty$ and $\tau$ is the relaxation time. From the least square fit to Eq. (7), the relaxation time of the adsorption process is calculated as $19.5 \mathrm{~s}$.

Fig. 4(a) shows the time dependence of experimental QCM frequency shifts (circles) for 3 cycles of adsorption and desorption process between $11 \% \mathrm{RH}$ and $84 \% \mathrm{RH}$ values. Fig. 4(b) shows the least square fit (solid line) of the adsorption parts of Fig. 4(a) using Langmuir adsorption isotherm model given in Eq. (7).

The average values of adsorption rate, was obtained to be $9.28 \pm 0.4 \mathrm{M}^{-1} \mathrm{~s}^{-1}$ and $0.04 \pm 0.0024 \mathrm{~s}^{-1}$, from the least square fit of adsorption part of the three cycle, respectively. 

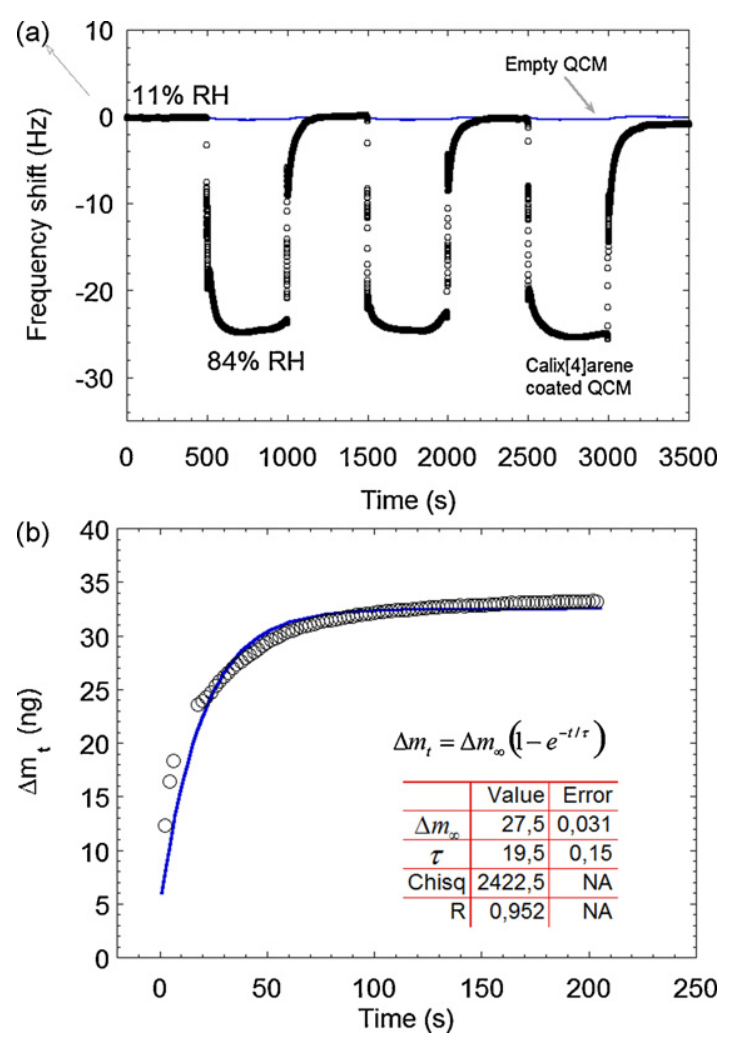

Fig. 4. Experimental QCM frequency shifts (circles) for 3 cycles of adsorption and desorption process between $11 \% \mathrm{RH}$ and $84 \% \mathrm{RH}$ values (a), and the least square fit (solid line) of the adsorption part given in (a) to the Langmuir adsorption isotherm model given in Eq. (7) (b).

The equilibrium constant, $K_{\text {equ }}$, for calix[4]arene film is determined using fit results as following,

$K_{\text {equ }}=\frac{k_{\mathrm{a}}}{k_{\mathrm{d}}}$

The Gibbs free energy $\Delta G$ of adsorption/desorption process in terms of $K_{\text {equ }}$ at a constant temperature is defined as [21]:

$\Delta G=-R T \ln K_{\text {equ }}$

The Gibbs free energy for both adsorption processes are calculated using Eq. (10) for each cycle. The $K_{\text {equ }}$ and Gibbs free energy for adsorption of 3 cycles are obtained as $211.83 \pm 5 \mathrm{~kJ} / \mathrm{mol}$ and $-13.11 \pm 0.6 \mathrm{~kJ} / \mathrm{mol}$, respectively. The negative sign shows that there is an energy loss for water molecules on calix[4]arene film surface, since the water molecules are adsorbed by the calix[4]arene film surface during adsorption process. For a favored (spontaneous) reaction, the change in the Gibbs free energy should be negative $(\Delta G<0)$. Hence, the kinetic analysis for calix[4]arene films shows a favored kinetic reaction with humidity molecules.

The QCM results show that calix[4]arene films are extremely sensitive to humidity and give reproducible adsorption kinetics against to humidity changes for short time intervals, due to sulphonate groups inducing solubility in water. The molecular sutructure of calix[4]arenes with sulphonate groups on the upper rim is quite proper to make strong complex with water molecules for water uptake, that causes mass change in the QCM electrodes.
Our experimental results also show that the calix[4]arene films are quite stable for humidity changes during measurements.

\section{Conclusion}

Calix[4]arene films with $40 \mathrm{~nm}$ thickness were obtained by spin coating technique. The response of calix[4]arene film to relative humidity change was investigated by QCM technique. The adsorption kinetics under constant relative humidity between $11 \%$ and $84 \%$ was explained using Langmuir absorption model at $22{ }^{\circ} \mathrm{C}$ constant QCM temperature. The average values of adsorption rate, desorption rate and equilibrium constant were obtained as $9.28 \pm 0.4 \mathrm{M}^{-1} \mathrm{~s}^{-1}$ and $0.04 \pm 0.0024 \mathrm{~s}^{-1}$ and $211.83 \pm 5$, respectively. The average Gibbs free energy for adsorption of 3 cycles is obtained as $-13.11 \pm 0.6 \mathrm{~kJ} / \mathrm{mol}$ resulting that the calix[4]arene films show a favored kinetic reaction against moist molecules in air.

\section{Acknowledgements}

S.O. thanks to Bedrettin Subaşılar for the valuable comments on the application of the Langmuir model during QCM data analysis. This research were partially supported by DPT (State Planning Organization of Turkey) under project number DPT2003K120390, Tubitak (Turkish Scientific Association) under project number TBAG 109T240 and Selcuk University Scientific Research Council (BAP).

\section{References}

[1] S. Sasaki, S. Aisawa, H. Hirahara, A. Sasaki, H. Nakayama, E. Narita, J. Eur. Cer. Soc. 26 (2006) 655

[2] S. Shinkai, S. Mori, T. Tsubaki, T. Sone, O. Manabe, Tetrahedron Lett. 25 (1984) 5315.

[3] S.I. Ohira, E. Wanigasekara, D.M. Rudkevich, P.K. Dasgupta, Talanta 77 (2009) 1814.

[4] F. Ozcan, M. Ersoz, M. Yilmaz, Mat. Sci. Eng. C 29 (2009) 2378.

[5] D. Filenko, Z. Kazantseva, K. Ivanova, O. Rabinovych, A. Kukla, Y. Shirshov, V.I. Kalchenko, I.W. Rangelow, Sens. Proceed. IEEE 2 (October 24-27) (2004) 669.

[6] T.H. Richardson, R.A. Brook, F. Davis, C.A. Hunter, Eng. Aspects 284-285 (2006) 320.

[7] D. Filenko, T. Gotszalk, Z. Kazantseva, O. Rabinovych, I. Koshets, Yu. Shirshov, V. Kalchenko, I.W. Rangelow, Sens. Actuators B 111-112 (2005) 264.

[8] J. Hartmann, J. Auge, R. Lucklum, S. Rösler, P. Hauptmann, B. Adler, E. Dalcanale, Sens. Actuators B, Chem. 34 (1-3) (1996) 305.

[9] V.I. Kalchenko, I.A. Koshets, E.P. Matsas, O.N. Kopylov, A. Solovyov, Z.I. Kazantseva, Yu.M. Shırshov, Mater. Sci. 20 (3) (2002).

[10] I.A. Koshets, Z.I. Kazantseva, Yu.M. Shirshov, S.A. Cherenok, V.I. Kalchenko, Sens. Actuators B 106 (2005) 177

[11] R. Ben Chaabane, M. Gamoudi, G. Guillaud, C. Jouve, R. Lamartine, A. Bouazizi, H. Maaref, Sens. Actuators B, Chem. 31 (1-2)(1996) 41.

[12] W.Z. Yang, R. Manek, W.M. Kolling, M. Brits, W. Liebenberg, M.M. De Villiers, Supramol. Chem. 17 (6) (2005) 485.

[13] G. Sauerbrey, Z. Phys. 155 (1959) 206.

[14] A. Casnati, Y. Ting, D. Berti, M. Fabi, A. Pochini, R. Ungaro, D. Sciotto, G.G. Lombardo, Tetrahedron 49 (1993) 9815

[15] L. Greenspan, J. Res. Natl. Stand.-A. Phys. Chem. 81A (January-February 1) (1977).

[16] D.S. Karpovich, G.J. Blanchard, Langmuir 10 (1994) 3315.

[17] S.J. Gregg, K.S.W. Sing, Adsorption, Surface Area and Porosity, Academic Press, London, 1967, ISBN 0-12r-r300956-1.

[18] Y.L. Sun, R.J. Wu, Y.C. Huang, P.G. Su, M. Chavali, Y.Z. Chen, C.C. Lin, Talanta 73 (2007) 857.

[19] P.G. Su, Y.P. Chang, Sens. Actuators B 125 (2008) 915.

[20] Y.A. Cengel, M.A. Boles, Thermodynamics an Engineering Approach, 5th ed., McGraw-Hill Science Engineering, 2006.

[21] S. Qiu, L. Sun, H. Chu, Y. Zou, F. Xu, N. Matsuda, Thin Solid Films 517/9 (2009) 2905. 